ORIGINAL ARTICLE

\title{
Improving journal clubs through the use of positive deviance: A mixed-methods study
}

\author{
Alexander Anzarut MD MSc CIP FRCSC ${ }^{1}$, Benjamin Martens BSc ${ }^{1}$, Edward Tredget MD MSc FRCSC ${ }^{2}$
}

\author{
A Anzarut, B Martens, E Tredget. Improving journal clubs through \\ the use of positive deviance: A mixed-methods study. Can J Plast \\ Surg 2011;19(3):82-84.
}

BACKGROUND: Plastic surgery journal clubs are often unsatisfactory for both surgeons and residents, leading to frustration and poor surgeon attendance.

OBJECTIVE: To assess and modify journal clubs using the principles of positive deviance.

METHODS: Surgeons and residents were surveyed across five domains before and after journal club modification. These included perception of the quality of articles chosen, the quality of the presentations, postpresentation discussions, educational benefit and overall satisfaction.

RESULTS: Using the principles of positive deviance, the authors were able to identify points of concern with journal clubs and make suggestions for improvement. Postintervention surveys demonstrated a statistically significant improvement in journal clubs across all five domains assessed. CONCLUSIONS: Using the principles of positive deviance, journal club satisfaction was improved. The interventions presented could be used to improve journal clubs at other institutions. In addition, the principles of positive deviance can be used to address a variety of administrative and educational challenges faced by plastic surgery programs.

Key Words: Education; Efficiency; Medical; Organizational; Organization and administration; Plastics; Surgery

Sir James Piaget and Sir William Osler developed and documented $\checkmark$ the first journal clubs in the mid-to-late 1800 s (1-3). Since then, not only has the depth and breadth of available articles increased exponentially, but also our understanding of, and acceptance and focus on practising evidence-based medicine has matured into what is now considered to be 'standard of care'. Journal clubs have been found to improve knowledge of clinical epidemiology and biostatistics, reading habits and use of medical literature in practice (2). Journal clubs also promote critical review of published literature (4) - an important consideration because not all published studies hold rigorous scientific standards (5).

Melchior and Meals (6) distributed a survey to American hand surgery fellows and fellowship directors, and found that as of 1998, only $86 \%$ of the responding programs had a journal club. The Royal College of Physicians and Surgeons of Canada suggests that journal clubs be included in residency programs as part of teaching in basic and clinical science, as well as critical appraisal of literature (4). All of the established plastic surgery residency programs in Canada have regular journal club meetings with mandatory attendance by residents (personal communications).

Despite their common implementation, journal clubs are often unsatisfactory for both the staff physicians and residents $(7,8)$. Thus, journal club organizers are often left with the challenge of improving club design and execution $(9,10)$ - a difficult task given the relative paucity of published information in this area. Currently, there are no published scientific articles addressing journal clubs in plastic surgery.

In the present study, we encouraged changes in journal club practise by soliciting recommendations from participating surgeons and residents using the principles of positive deviance. We combined qualitative and quantitative methods to identify whether and how we

\section{Améliorer les clubs de lecture grâce à la déviance positive : une étude aux méthodes mixtes}

\begin{abstract}
HISTORIQUE : Les clubs de lecture en chirurgie plastique sont souvent insatisfaisants, tant pour les chirurgiens que pour les résidents, ce qui suscite de la frustration et une faible participation des chirurgiens.

OBJECTIFS : Évaluer et modifier les clubs de lecture grâce aux principes de la déviance positive.

MÉTHODOLOGIE : Les auteurs ont sondé des chirurgiens et des résidents dans cinq domaines, avant et après les modifications aux clubs de lecture. Ces derniers sont la perception de la qualité des articles choisis, la qualité des présentations, les discussions après les présentations, les avantages pour la formation et la satisfaction globale.

RÉSULTATS : À l'aide des principes de la déviance positive, les auteurs ont pu déterminer les insatisfactions à l'égard des clubs de lecture et faire des suggestions d'amélioration. Les sondages effectués après l'intervention ont démontré une amélioration statistiquement significative des clubs de lecture dans les cinq domaines évalués.

CONCLUSIONS : À l'aide des principes de la divergence positive, la satisfaction envers les clubs de lecture a augmenté. Les interventions présentées pouvaient être utilisées pour améliorer les clubs de lectures d'autres établissements. De plus, les principes de la divergence positive peuvent être utilisés pour régler divers problèmes d'administration et de formation au sein des programmes de chirurgie.
\end{abstract}

were able to impact journal clubs. We hypothesized that participants who play an active role in refining journal club practice would be more likely to embrace these changes and, ultimately, be more satisfied with the educational value of journal club sessions.

\section{METHODS}

A mixed-methods survey that contained quantitative and a qualitative components was developed. The quantitative component assessed the level of satisfaction and quality of journal club sessions across five domains: the quality of articles chosen, presentations, postpresentation discussions, educational benefit and overall satisfaction of the journal clubs. Participants responded using a 7-point Likert scale, which ranged from 1 to 7 ( 1 - terrible; 2 - poor; 3 - below average; 4 average; 5 - above average; 6 - excellent; and 7 - outstanding). The survey also included a qualitative component, in which participants could write their concerns, comments and suggestions.

In the first phase of the study, the survey was distributed at the first journal club of the academic year. The qualitative responses were analyzed to identify areas for improvement in journal club design, content and overall value. In the second phase, goals were formalized for the design of a new journal club. Several changes were made to the conduct of the journal club. A standard presentation template was developed to guide and streamline presentations according to the obtained suggestions. Nine months after implementation of the new journal format, the same survey was readministered. This was referred to as the postintervention survey, and was compared with the preintervention survey. Independent sample $t$ tests were conducted to compare journal club satisfaction across each domain before and after the intervention; $\mathrm{P}<0.05$ were considered to be significant.

${ }^{1}$ Division of Plastic Surgery, Department of Surgery, University of British Columbia Island Medical Program, Victoria, British Columbia;

${ }^{2}$ Division of Plastic Surgery, University of Alberta, Edmonton, Alberta

Correspondence: Dr Alexander Anzarut, Beverly Medical Clinic, Suite 201 - 2763 Beverly Street, Duncan, British Columbia V9L 6X2.

Telephone 250-597-3390, fax 250-597-1297, e-mail alex.anzarut@gmail.com 


\section{RESULTS}

A total of 13 preintervention and 17 postintervention surveys were collected. Due to on-call requirements and vacations, not all surgeons and residents were present at the first journal club.

Qualitative analysis revealed the following participant concerns:

...the articles chosen by the residents were lacking clinical relevance...discussions lacked clinical importance...assessment of an article's scientific method took precedence over overall importance of clinical ideas presented...the actual length of journal club took too long... and discussions were long and rambling.

The formalized goals of the journal club were the following:

To present relevant information that may influence clinical decision making and the quality of care provided by the Division of Plastic Surgery, to teach resident staff how to concisely summarize and present research articles, and to teach all participants the skills necessary for critical appraisal of the literature.

To address the concerns related to the choice of article, articles were still chosen by residents, but had to be subsequently endorsed by a surgeon, who would provide insight and direction. To address time efficiency, rigid timing was introduced. Participants would meet for food and drinks from 19:00 to 20:00, article presentation would begin at 20:00 and end at 21:30, and be limited to 6 min per presentation and $9 \mathrm{~min}$ for ensuing questions and discussion.

A standard format was provided as a template to help encourage concise summarization of important aspects including background, objectives, design, methodology, results and strength of conclusions. To help provide context for the article, each presenter was asked to comment on what was previously known on the subject, what the article contributed to the area and how the findings might change patient care. Recognizing that the majority of staff and residents had little formal training in critical appraisal of the literature, a series of short reviews on evidence-based medicine were presented (11).

The quantitative results for satisfaction in the various domains are summarized in Figure 1. There was a significant difference in the mean Likert score for satisfaction with the quality of the article chosen, the presentation, the postpresentation discussion, the venue, the educational benefit and the overall satisfaction with the journal club between the preintervention assessment and the postintervention assessment. These results demonstrate that the technique of positive deviance and interventions applied produced a statistically significant increase in the satisfaction and quality of plastic surgery journal clubs. This was true for all of the domains assessed.

The qualitative results from the follow-up survey supported this improved satisfaction. They also provided insight into how the interventions improved journal clubs. Participants reported that "the new format is a major improvement", and "the consistent and logical nature of the presentations and discussions have made it much easier to gain educational benefit".

\section{DISCUSSION}

Using the principles of positive deviance, we were able to significantly improve journal clubs. By involving all journal club participants in the changes to journal clubs, we were able to develop a set of formalized goals, implement change and, ultimately, improve the educational value and overall satisfaction with plastic surgery journal club sessions. Other studies and reviews of journal clubs focused explicitly on curriculum-based outcomes including reading habits, critical appraisal skills, knowledge expansion, fluency with biostatistics, epidemiology and methodology, and keeping up with current literature $(9,12)$. The increasing volume of plastic surgery literature being published, and the increasing focus on the analysis of evidence-based methodology can lead to a decrease in journal club satisfaction. Clinicians may feel they are attending a statistical meeting rather than a continuing medical education event. It is the organizers' responsibility to improve

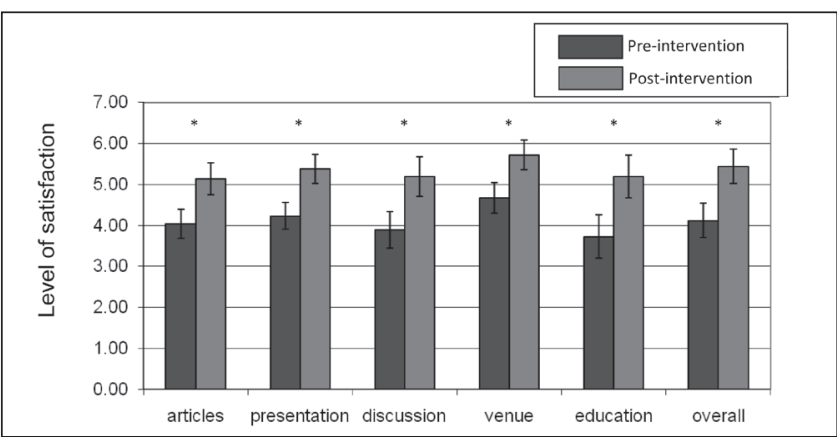

Figure 1) Preintervention (dark columns) and postintervention (lighter columns) satisfaction scores. *All comparisons are statistically significant with $P<0.05$

participant satisfaction; however, there are very few published strategies to turn to $(7-10)$.

The principle of 'positive deviance' is that individuals who would be required to change are the ones asked for ideas on how to change, and thus encouraged to fully 'buy in' to the process of changing. In this way, participants build on capabilities they already have, rather than imposing change (13). The principle of positive deviance has been successfully implemented in other areas of medicine. At a Pittsburgh veteran's hospital (USA), increased hand sanitization rates and decreased methicillin-resistant Staphylococcus aureus wound infection rates were achieved using positive deviance (14). Instead of dictating how change should happen, they said, "We're here because of [this problem], and want to know what you know about how to solve it (13)". What resulted was a highly engaged staff, with strong motivations to change. The results of this strategy were staggeringly successful $(13,15)$.

By combining both quantitative and qualitative methodology, we were able to show improvement in journal clubs and what caused the improvement. Most studies in the plastic surgery literature focus on the use of statistics to show whether an intervention made a significant change. However, few studies collect qualitative data to identify why the intervention produced a change. By collecting and analyzing qualitative data, we found that journal club satisfaction increased because of improved flow of the presentations, a better balance between discussion of methodology and clinical importance, and a limit to the length of the discussions.

The present study had two major limitations. First, our study included a small sample size. However, we did identify a statistically significant change in each of the domains assessed. Second, our study included a single plastic surgery division. However, based on our review of the literature, the challenges faced by our division have been reported across a variety of disciplines and geographical locations. This suggests that our findings can apply to other plastic surgery divisions.

\section{CONCLUSION}

Using the principle of positive deviance and a mixed-methods research design, we showed a statistically significant improvement in plastic surgery journal clubs in each of the domains assessed.

FINANCIAL SUPPORT: Dr Alexander Anzarut receives support from the University of British Columbia Island Medical Program. Dr Benjamin Martens has no conflicts of interest to declare related to the information presented in this article.

\section{REFERENCES}

1. Linzer M. The journal club and medical education: Over one hundred years of unrecorded history. Postgrad Med J 1987;63:475-8.

2. Ebbert JO, Montori VM, Schultz HJ. The journal club in postgraduate medical education: A systematic review. Med Teacher 2001;23:455-61. 
3. Crank-Patton A, Fisher JB, Toedter LJ. The role of the journal club in surgical residency programs: A survey of APDS program directors. Curr Surg 2001;58:101-4.

4. Royal College of Physicians and Surgeons of Canada. General Standards of Accreditation <http://rcpsc.medical.org/ residency/accreditation/genstandards_e.pdf $>$ (Accessed on July 11, 2010).

5. Ioannidis JPA. Why most published research findings are false. PLoS Med 2005;2:e124.

6. Melchior JA, Meals RA. The journal club and its role in hand surgery education. J Hand Surg 1998;23:972-6.

7. Hartzell JD, Veerappan GR, Posley K, Shumway NM, Durning SJ. Resident run journal club: A model based on the adult learning theory. Med Teacher 2009;31:156.

8. Moberg-Wolff EA, Kosasih JB. Journal clubs. Prevalence, format, and efficacy in PM\&R. Am J Phys Med Rehabil 1995;74:224-9.

9. Dirschl DR, Tornetta, P, Bhandari M. Designing, conducting, and evaluating journal clubs in orthopaedic surgery. Clin Orthopaed Rel Res 2003;413:146-57.
10. Burstein JL, Hollander JE, Barlas D. Enhancing the value of journal club: Use of a structured review instrument. Am J Emerg Med 1996;14:561-3.

11. Guyatt GH, Rennie D. Users' Guides to the Medical Literature: A Manual for Evidence-Based Clinical Practice. American Medical Association Press, 2002.

12. Deenadayalan Y, Grimmer-Somers K, Prior M, Kumar S. How to run an effective journal club: A systematic review. J Eval Clin Pract 2008;14:898-911.

13. Gawande A. Better: A Surgeon's Notes on Performance, 1st edn. New York: Metropolitan, 2007.

14. Ellingson K, Muder RR, Jain R, et al. Sustained reduction in the clinical incidence of methicillin-resistant Staphylococcus aureus colonization or infection associated with a multifaceted infection control intervention. Infect Control Hosp Epidemiol 2011;32:1-8.

15. Singhal A, Greiner K. 'When the task is accomplished, can we say we did it ourselves?'A quest to eliminate MRSA at the Veterans Health Administration's Hospitals in Pittsburgh. <www.communicationforsocial change.org/pdfs/Arvind-Greiner-Mazi12.pdf> (Accessed on June 4, 2011). 